\title{
Distribution of Larvae of Pinnixa rathbuni SAKAI (Decapoda: Pinnotheridae) in Ise Bay and Its Neighbouring Coastal Waters, Central Japan
}

\author{
Hideo SEKIGUCHI ${ }^{* 1}$ \\ (Received July 26, 1978)
}

\begin{abstract}
The objects of this study are to clarify the temporal and areal distribution of larvae of Pinnixa rathbuni in Ise Bay and its neighbouring coastal waters, and to determine to what extent the final ecdysis into megalops takes place in water without drifting into the oceanic environment.

The larvae were found in November to March of the following year. Early zoeal larvae appeared at first abundantly in November, and then abundant megalops were found in February of the next year, with the result that the length of the larval period in the plankton was approximately 120 days. This period is from two to four times that required for the larval development of the pinnotherid crabs synbiotic with invertebrates.

The larvae were found abundantly in Ise Bay and Mikawa Bay, but they were not met with in the open coastal and oceanic waters except the area near the mouth of the bays. This suggests that the larval dispersal into the open coastal and oceanic region does not considerably influence the loss of the larval population from the bays.
\end{abstract}

Among 38 species of Pinnixa genus 5 species have been known from Japan, although nearly all the pinnixids are commensals or symbiotic with invertebrates. ${ }^{11}$ Pinnixa rathbuni is one of the most popular benthic crabs and is an important food for several fishes there., ${ }^{2,31}$ The species breeds from early summer to autumn. Then, the free-living stages (zoea and megalopa) develop and enter the benthic life at the first juvenile crab stage in the spring next year." In the free-living stages of the crab, which passes through 5 zoeal, one megalopic and first juvenile crab stage, ${ }^{* 2}$ the crab is extremely abundant in Ise Bay on the Pacific coast of central Japan, where it forms the major component in the zooplankton biomass during autumn to winter season. "There are, of course, other pinnotherid crabs in the bay, but the larvae of $P$. rathbuni by far out-number other pinnotherid larvae in the zooplankton sample. The free-living stages of $P$. rathbuni seem not to be taken by planktivorous fishes due to their spiny forms, and would not have predators which controll their standing stock seriously in the bay. Abundant populations of the free-living stages would be "unuseful" animal in production made available by planktivorous fishes in the bay, and then they compete directly with the fishes for available foods. ${ }^{51}$ The general biology of $P$. rathbuni has been scarcely elucidated in detail until now. Some aspects of the ecology were re- ported for the benthic life of the juveniles and adults of the crab."

The objects of this investigation are to clarify the temporal and areal distribution respectively of 5 zoeal and one megalopic stages of this important crab in Ise Bay and its neighbouring coastal waters, and to determine to what extent the larvae enter the first juvenile crab stage without drifting into the oceanic environment.

\section{Studying Area and Materials}

Studying area and sampling stations are shown in Fig. 1. The water in the bays is rich in nutrient and highly turbid due to the freshwater discharge and sewage effluent from the cities. Gravel, sand and sandy mud bottoms cover the western parts of Ise Bay and near the mouth of the two bays and neighbouring coastal waters along the Pacific coast. Other areas of the bays have mud bottoms, where $P$. rathbuni has never been found. ${ }^{21}$ In the contrast to the bay benthic community elucidated thirty years ago by MrYADr, ${ }^{2)}$ the crab decreases drastically in numbers and in habitat areas, while polychaetes have been commonly found with recent progress of eutrophication in the bays. ${ }^{61}$

Monthly oceanographic and biological surveys of the bays and neighbouring coastal waters have been carried out for the last years by the Ise-wan

\footnotetext{
*1 Faculty of Fisheries, Mie University, 2-80 Edobashi, Tsu, Mie (関口夸夫：三垂大学水産学部).

*2. H. SekIGUCAI: to be published.
} 


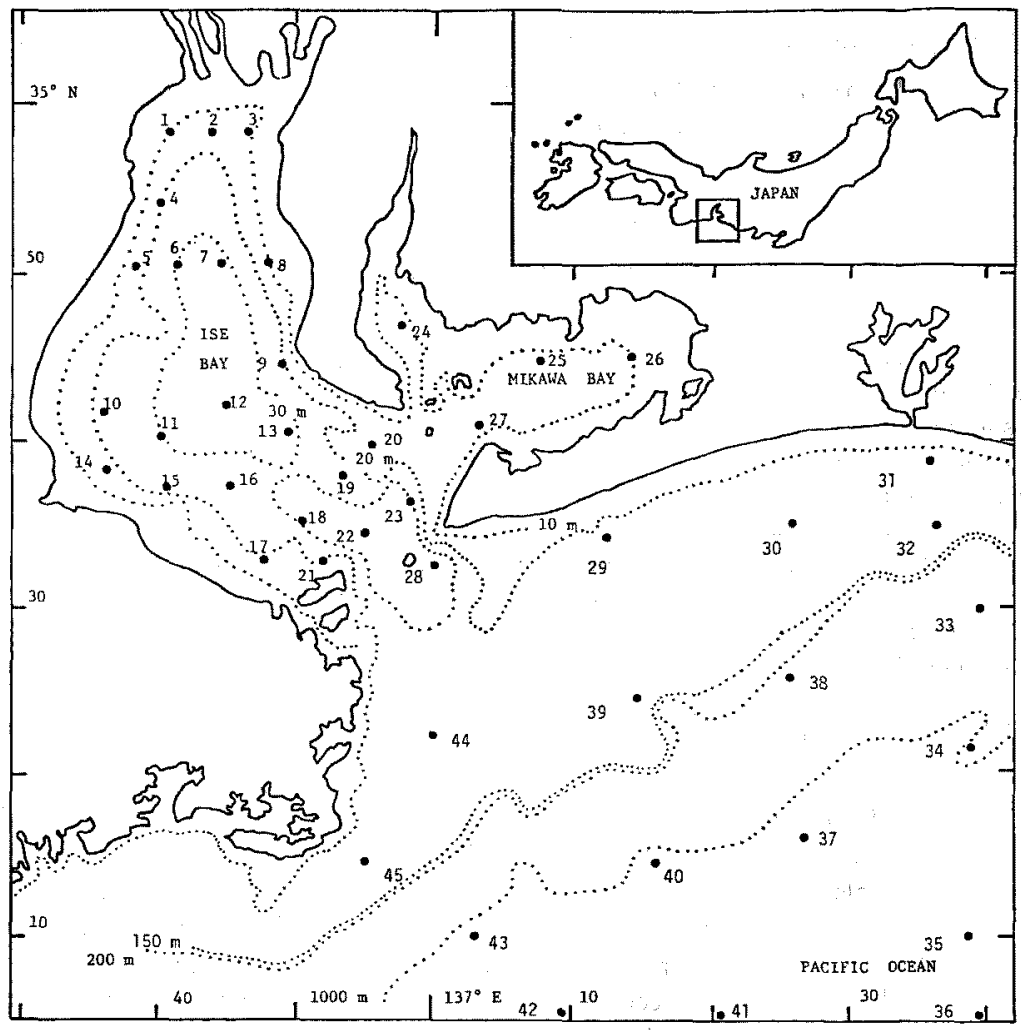

Fig. 1. Map of area studied and sampling stations.

and Aichi Fisheries Research Laboratories. Zooplankton was sampled at 23 stations in Ise Bay, at 4 stations in Mikawa Bay and at 18 stations in the neighbouring open coastal waters along the Pacific coast from October 1976 to March 1977 (Fig. 1) by a Marutoku plankton net, $45 \mathrm{~cm}$ in diameter and $0.33 \mathrm{~mm}$ mesh-openings. It has been revealed that the larvae of $\boldsymbol{P}$. rathbuni are always found only during the period of November to March next year." ${ }^{5 !}$ The net was hauled vertically from the depth of $150 \mathrm{~m}$ level (from bottom in the shallower region) to surface at each station. In processing the sample, the larvae of $P$. rathbuni were sorted into zoea I-V stages and one megalopa, and then numbers of them were counted from each collection.

A zooplankton net is not ideal instrument for collecting the crab larvae since a degree of net avoidance certainly occurs, and for this reason data have not been transformed to numbers per standard volume. And so numbers per net haul have been used for showing the dispersal of the larvae released from the benthic population of the crab. There is no evidence determining whether the larvae migrate diurnally so that they would descend during the daytime bellow the $150 \mathrm{~m}$ level sampled. This problem will be discussed afterward.

\section{Results}

The larvae of $P$. rathbuni were not met with in the zooplankton sample collected in October (Table 1). The data for the larvae from November 1974 to March 1975 is also incorporated into Table 1.

The temporal and areal distribution of the larvae is shown in Fig. 2. Zoea I larvae were taken in November to December, although peak abundance was in November. Same pattern was seen for zoea II larvae. They appeared only at Stns. 9 and 12, with the highest numbers of 237 (zoea I) and 1347 inds./net haul (zoea II). Zoea III and IV larvae appeared in November to January next year; zoea III larvae were most abundant at Stn. 9 in November with the highest numbers of 4093 
Table 1. Total catch composition of larval forms of Pinnixa rathbuni in Ise Bay and its neighbouring coastal and oceanic waters, central Japan

\begin{tabular}{|c|c|c|c|c|c|c|c|c|c|c|c|c|c|c|c|c|c|c|c|c|c|}
\hline & & \multicolumn{7}{|c|}{ Ise Bay } & \multicolumn{6}{|c|}{ Mikawa Bay } & \multicolumn{7}{|c|}{ Coastal and oceanic waters } \\
\hline & & \multicolumn{5}{|c|}{ Zoea } & \multirow{2}{*}{$\begin{array}{c}\text { Mega- } \\
\text { lopa }\end{array}$} & \multirow{2}{*}{ Total } & \multicolumn{4}{|c|}{ Zoea } & \multirow{2}{*}{$\begin{array}{l}\text { Mega- } \\
\text { lopa }\end{array}$} & \multirow{2}{*}{ Total } & \multicolumn{5}{|c|}{ Zoea } & \multirow{2}{*}{$\begin{array}{c}\text { Mega- } \\
\text { lopa }\end{array}$} & \multirow{2}{*}{ Total } \\
\hline & & $\mathbf{I}$ & II & III & IV & $\mathrm{v}$ & & & I II & II III & IV & $\mathrm{v}$ & & & I & II & III & IV & $\mathrm{V}$ & & \\
\hline Nov. & 1974 & 38 & 83 & 549 & 32 & 6 & 0 & $708(26)$ & & & & & & & & & & & & & \\
\hline Dec. & & 0 & 5 & 52 & 1159 & 2671 & 5 & $3892(150)$ & & & & & & & & & & & & & \\
\hline Jan. & 1975 & 0 & 0 & 0 & 564 & 2993 & 2114 & $5671(210)$ & & & & & & & & & & & & & \\
\hline Feb. & & 0 & 0 & 0 & 25 & 222 & 1131 & $1378(53)$ & & & & & & & & & & & & & \\
\hline Mar. & & 0 & 0 & 0 & 0 & 31 & 132 & $163(6)$ & & & & & & & & & & & & & \\
\hline Total & & 38 & 88 & 601 & 1780 & 5923 & 3382 & & & & & & & & & & & & & & \\
\hline Nov. & 1976 & 237 & 1347 & 4190 & 147 & 0 & 19 & $5933(258)$ & $\begin{array}{ll}0 & 0\end{array}$ & $0 \quad 0$ & 0 & 0 & 0 & $0(0)$ & 0 & 0 & 0 & 0 & 0 & 0 & $0(0)$ \\
\hline Dec. & & 12 & 165 & 644 & 1024 & 1802 & 56 & $3693(161)$ & 011 & 1102 & 1347 & 308 & 0 & $1768(442)$ & 0 & 0 & 0 & 26 & 2 & 0 & $28(2)$ \\
\hline Jan. & 1977 & 0 & 0 & 22 & 257 & 1627 & 1020 & $2916(127)$ & 00 & $0 \quad 20$ & 64 & 708 & 481 & $1273(318)$ & 0 & 0 & 16 & 201 & 159 & 0 & $195(11)$ \\
\hline Feb. & & 0 & 0 & 0 & 0 & 204 & 1151 & $1357(59)$ & 00 & $\begin{array}{ll}0 & 0\end{array}$ & 0 & 14 & 20 & $34(9)$ & 0 & 0 & 0 & 0 & 3 & 1 & $4(+)$ \\
\hline Mar. & & 0 & 0 & 0 & 0 & 0 & 594 & $594(26)$ & 00 & $\begin{array}{ll}0 & 0\end{array}$ & 0 & 0 & 0 & $0(0)$ & 0 & 0 & 0 & 0 & 0 & 0 & $0(0)$ \\
\hline Total & & 249 & 1512 & 4856 & 1428 & 3633 & 2840 & & 011 & 11122 & 1411 & 1030 & 501 & & 0 & 0 & 16 & 461 & 162 & 1 & \\
\hline
\end{tabular}

Ise Bay: 27 sampling stations in Octoter 1974 to March 1975, and 19 sampling stations in October 1976 to March 1977 Mikawa Bay: 4 sampling stations

Coastal and oceanic waters: 18 sampling stations

The numbers in parentheses indicate average incls./net haul. 


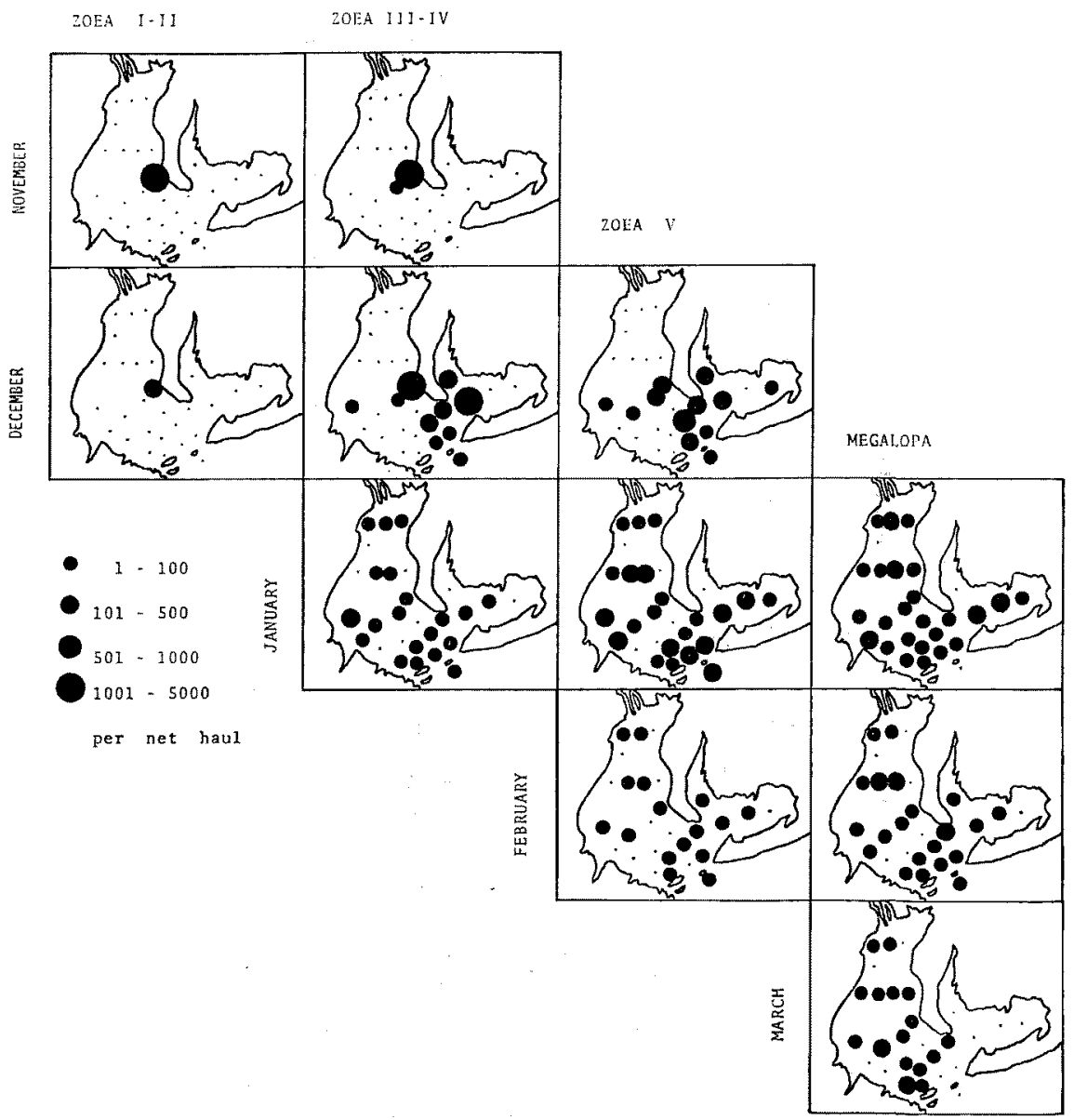

Fig. 2. Temporal and areal distribution of zoeal and megalopic stages of Pinnixa rathbuni from November 1976 to March 1977.

inds./net haul. The highest numbers of zoea IV larvae, 515 inds./net haul, was found at Stn. 9 in December. Their distribution was still confined in the area around Stn. 9. In December, it was extended southward in Ise Bay and further into Mikawa Bay. Then, the distribution was extended to the whole area of the two bays in January. Zoea V larvae appeared in December to February next year; peak abundance was found in December, with the highest numbers of 730 inds./net haul at Stn. 19 in the southern area of Ise Bay. They were not taken at first in the innermost parts of Ise Bay, and then they appeared in the whole area of the bays. Megalopic larvae appeared in January to March; the highest numbers, 346 inds./net haul, was found at Stn. 7 in the eastern part of Ise Bay. The distribution was extended to nearly all the stations in the bays. They disappeared from the zooplankton samples collected from Mikawa Bay in March. The larvae of zoea to megalopa could not found in the open coastal waters along the Pacific coast except Stn. 28 near the mouth of the bays.

It would be understood from the distribution of the benthic populations of $P$. rathbuni that zoea I to III larvae were not taken in the innermost parts of Ise Bay and in Mikawa Bay during November. The benthic populations of the crab occur on gravel, sand and sandy mud bottoms on the western and southern parts of Ise Bay and in the mouths of the bays, but they have been found neither on mud bottoms in the northern, eastern and central parts of Ise Bay nor in Mikawa Bay. The evidence can be summarized as follows; con- 
sidering from the areal distribution pattern of the larvae (Fig. 2), the noticable fact is that the variation of their distribution showed a clockwise movement in Ise Bay. The larvae which would hatch out in the area around Stn. 9 in Ise Bay spend their life in this area, but then their distribution is splitted; one is extended toward south to east into Mikawa Bay, and the other toward the central to western parts of Ise Bay during the development. Thus, the larvae are found more or less evenly in the whole area not only in the bays but in the open coastal waters near the mouth of the bays. Clockwise movement of the larval distribution was also observed in the samples collected from Ise Bay during 1974 to 1975 calendar year, when, as made clear in the present study, abundant zoea I to III larvae were found only at Stn. 9 in the bay in November. ${ }^{5}$ ? This would mean that they are not by chance to be found at first abundantly around the area of Stn. 9. Unfortunately, the question is open whether this clockwise movement of the larval distribution would be related with the water movement of the bay, for we have not yet detailed informations on that during autumn to winter of the bay. This problem can not be elucidated until the general water movement of the bay would be known simultaneously with diurnal vertical migration of the larvae.

Abundant zoea I larvae, for the first time, appeared in the water during November and then megalops were found in peak abundance in February next year. This indicates that the length of the larval period in the plankton is approximately 120 days. This period is from two to four times that required for the larval development of symbiotic crabs with the invertebrates."

It would be reflected in the total catch composition of the larvae (Table 1) that the duration of the larval stages of the crab should vary considerably. It would be unrealistic to use these figures to make estimates of mortality rates, because it is unknown whether all stages involved were equally well sampled. Early larvae appeared over a much smaller area than in older larvae (Fig. 2). So zooplankton net would be a more efficient sampler of early larvae than older larvae, sparse and relatively efficient avoiders of nets.

\section{Discussion}

The larvae of $P$. rathbuni were not found in the open coastal and oceanic waters along the Pacific coast except the area near the mouth of the bays
(Fig. 2). This phenomenon may be produced due to the larvae descending during the daytime bellow the $150 \mathrm{~m}$ level sampled. Data are still much meagre for their diurnal vertical migration. Judging from that sampling stations of $28-32,39$, 44 and 45 are located in the open coastal region shallower than the $150 \mathrm{~m}$ level sampled (Fig. 1), it is concluded to be not artificial due to sampling methods that the larvae were not found in the open coastal and oceanic waters except the area near the mouth of the bays. Then, this suggests that the larval dispersal into the open coastal and oceanic region would not influence considerably on the loss of the larval populations from the bays. Reasonable explanations are not immediately apparent why the larval dispersal into the open coastal and oceanic region would not be considerable. To understand the mechanism maintaining the larval populations within the bays, we must have more informations on the water movement of the deep layers near the mouth of the bays and further on their vertical distribution. The larvae positively extend their distribution into the innermost parts of Ise Bay and into Mikawa Bay. The benthic populations of the crab, however, have not been found in these areas presumably because of the conditions related intimately with mud bottoms. ${ }^{21}$ Recently, with the progress of eutrophication the habitats of the benthic populations of the crab have been drastically uncomfortable due to depletion of disolved oxygen contents developing in these bay bottoms during warm seasons. This situation would comfort to increase of the polychaetes there in parallel with perishment of the benthic population of the crab. ${ }^{6}$ Apart from mortality during the free-living stages, the bay populations of the crab would have a critical period during the first juvenile crab stage which settle the bottoms and contact very often with uncomfortable habitats of the bay bottoms for them.

Deducing from that abundant benthic populations of $P$. rathbuni have been always met with in the western parts of Ise Bay, ${ }^{2,6)}$ we might expect that early larvae of the crab appear at first in the western parts of the bay during the period of reproduction. But in fact they always appeared abundantly at first at Stn. 9 in the eastern parts of the bay. The reason why they appear abundantly at first not in the western parts but in the eastern parts of the bay is not immediately apparent. The ecology of the benthic population of the crab, especially that during a prolonged breeding period, 
should be elucidated for better understanding the distribution of early larvae in Ise Bay.

A prolonged breeding period has been noted in other pinnotherid crabs. ${ }^{47}$ Except $P$. rathbuni, bi-annual reproduction is a characteristic of all symbiotic pinnixids among which the winter period of reproduction is the more successful. The larvae of $P$. rathbuni are larger than those of others and so the length of the larvae period is from two to four times that required for the larval development of the symbiotic pinnixids where some of them begin to infect into the invertebrates during megalopic stage." These facts may be related intimately with the benthic life of $P$. rathbuni much different from other pinnixids.

\section{Acknowledgements}

The author heartly thanks the members of the Ise-wan and Aichi Prefectural Fisheries Research Laboratories for collecting samples.

\section{References}

1) T. SAKAI: Sci. Rep. T. B. D. Sect. B, 2, 37-43 (1934).

2) D. MIYADI: Memoirs Imperial Mar. Obser., 7, 503-524 (1941).

3) M. OMORI: Bull. Japan. Soc. Sci. Fish., 40, 1115-1126 (1974).

4) G. Yamamoto, R. Kitamori, M. Nishimira, I. SHISHIDO, and T. HABE: Interium Rep. JIBP. $P M ., 4$, 39-48 (1971).

5) H. Sekiguchi: Bull. Japan. Soc. Sci. Fish., 43, 239 (1977).

6) R. Kitamori, T. Sugrno, and T. Sawada: In "Report of the Survey for Developing Fisheries in the Recess of Ise Bay" (ed. by Ise-wan Fisheries Research Laboratory), Vol. 1, Mie, 1970, pp. 5-40.

7) J. B. Pearce: In "Some Comtemporary Studies in Marine Science" (ed. by H. Barnes), George Allen and Unwin, London, 1966, pp. 565-589. 